\title{
An Exploratory Theoretical Framework based on the Interactive Marketing Model of Industrial Products based on user Innovation
}

\author{
Fangfang Shao ${ }^{1, a^{*}}$ and Jing $\mathrm{Ai}^{1, \mathrm{~b}}$ \\ ${ }^{1}$ School of Management,Wuhan University of Technology,Wuhan,P.R.China,430062 \\ a1248485063@qq.com, b1049701048@qq.com
}

Keywords: Interactive marketing; Innovative users; User Participation; Industrial marketing

\begin{abstract}
. interactive marketing is developing rapidly due to the importance of special marketing demand and the development of information technology. This paper introduces innovative users as key variables into the industrial product marketing model. Transfer the interactive marketing to industrial marketing, and try to build an interactive marketing mode based on user innovation in the case of industrial marketing. The model can effectively solve the wrong information between enterprises and users, imbalance between supply and demand, the problem of unmarketable products and complete the customer relations management theory in the existing industrial marketing which can't solve the problem of dynamic, enrich the knowledge of industrial marketing.
\end{abstract}

\section{Introduction}

Since the 1970 s, professor Eric von Hipple professor confirms the innovation source diversity through a large number of empirical studies of some industries, he observed the main body of innovation is not limited in the aspect of manufacturers, users can also become innovators.

With the continuous progress of the society, the market competition gradually transforms from the traditional marketing mode to the customer-drivenmarketing mode. That is, a kind of enterprise and user interactive learning marketing mode transformation. Whether it is business practitioners or theoretical research scholars have begun to realize that the difference between industrial marketing and consumer goods marketing in the theoretical level of the gap is very obvious. Unlike consumer goods marketing, industrial product marketing decision-making generally has a number of decision-making committees or decision-making centers, and the relationship between buyers and sellers is more complex and longer. The economic and social effects of industrial marketing have fully demonstrated the need for specialized theoretical research on industrial marketing [1].

In this paper, the interactive marketing model of industrial products functions mainly through the supplier and the user's information exchange, emotional exchange to achieve interaction. However, in the process of user demand satisfaction, there exists information transmission problems. This is a problem that traditional users cannot solve in the innovation field, and must be analyzed from the perspective of marketing, especially interactive marketing. Establish an interactive marketing model based on user innovation[2], and use it to solve the problem of asymmetric information between users and enterprises and the problem of unmarketable products, thus expand the research scope of interactive marketing

\section{Literature Review}

Interactive Marketing. Pan Gushan, Chen Chen. xing (2001)[3] pointed out that the interactive marketing refers to the enterprise should try to offer more than the functional benefits of benefits to consumers, extending marketing activities to the marketing process of the product before, during and after, and strengthen the interaction with consumers at various levels to cultivate the relationship with consumers. Wang Ting, Lu Shuang (2003) [4]pointed out that the theory of customer relationship disintegration. Ramani and Kumar (2008)[3] defined the interactive orientation for the first time in the study, and developed a corresponding measurement scale. He Guozheng (2008) [5]points out that customer participate in designing a wide range of activities 
between customers and suppliers, including providing intellectual, economic, or physical contribution for the enterprise development of new product or service .

At present, the value of co-creation has become a very important concept in service marketing (Lovelock and Wirtz, 2004) ${ }^{[3]}$. Corporate marketing should focus on how to interact with customers and allow customers to experience and enjoy the process of co-creation (Zhou Jianheng, 2009$)^{[5]}$

User Innovation. User innovation is a very important research field in enterprise innovation theory. Von Hipple (1976, 1977)[2] proposed a revolutionary view of "the user is an innovator" and conducted an in-depth study of the user's innovation, and then he proposed that innovation be divided into: Manufacturer innovation and supplier innovation based on the link between innovation and innovator . Rosenberg(1982) put forward the concept of "learning in use"[2], that is, usually performed by the user during the use of the product to solve the problem of the task. Gales and Mansour (1995) validated a significant positive correlation between user participation in innovation projects and innovation project success rates, and stressed that the degree of user involvement must match the degree of uncertainty and the environment of the project. Wu Guisheng, Xie Wei (1996) [6]pointed out that the user innovation refers to the user's innovative activities throughout the processes of useage, including put forward new ideas, new equipment, tools, materials, technology and so on that aim to achieve their own purposes.

Von Hipple $(2005)^{[2]}$ further argues that with the advent of the era of knowledge economy and the emergence of advanced technology, user innovation will be further developed in the new book "Innovative Democratization".

\section{Case Study - Taking Michelin Tires as an Example}

Michelin was founded in 1888 in the French Clermont-Ferrand. For more than 100 years, Michelin has undergone continuous innovation and development. Now has the world's five continents of the business operations and located in Europe, North America and Asia R \& D center. guides.Different from other industrial enterprises, Michelin tires to create performance activities by creatively putting in the user innovation activities. in addition to production activities and marketing activities. With the advent of the Internet age, corporate marketing and production activities must be "push" and "pull" combination. Enterprises should not only control costs, improve product quality, but also positive contact with consumers, timely access to user needs and expectations, to maintain frequent contact with the user..In addition to the technology keeping up with the times, Michelin's success also depends on its innovative interactive marketing model.

(1) To Build a Platform to Enhance the Convenience of User Participation, Which is the Basis for Interaction between the Two Sides. As people gradually realized the personal time and energy scarcit, in order to improve efficiency, enterprises pay more attention to the use of various media, the use of modern developed information technology, especially the Internet as a platform for interactive marketing[7]. For Michelin, the specific approach is: to choose or build enterprise network marketing platform, which is the forefront of enterprise network marketing. With its own website, Michelin can effectively carry out all kinds of targeted and timely online marketing activities, which will make the communication with the users practical. Its official website provides store information, tire safety knowledge, user feedback and other columns, which greatly enhances the communication convenience with users. Different from consumer marketing, the "platform" in the interactive marketing of industrial products not only refers to the website, but also a "carrier". Firms not only need communication platform carrier such as website, but also can be good product, good project work carrier.

(2) User and User Network. This case draws on two basic assumptions established in the Payne relational market model: one is to keep older users more valuable than to attract new users, and to establish and maintain relationships with users to benefit both parties. In general, industrial buyers usually have more professional skills than buyers of consumer goods of judging product quality and function[8] so the Michelin tyre adopted corresponding marketing strategy and the matching, Michelin regularly held in store member salons over the weekend, the professional and technical personnel and senior management of the company and the user face to face communication. In 
addition, the Michelin community connects users to form a user tribe to establish a long-term relationship with customers through interactive marketing, then establish a learning relationship with each user, especially"innovative user"., that is ,persuasive users with higher function demands in the industry .In the process of interaction with users, enterprises constantly acquire information about user needs and experiences, improve products and services, and improve the performance of enterprises..

(3) To Provide a Higher User Experience, to Achieve User Achievement. The user experience is particularly important in the interactive marketing model. Michelin tires in Shanghai, Guangzhou and Beijing, Wuhan and other major cities in the main road set up a relatively dense distribution of stores that has Michelin featured products and accessories. When users are in shopping, professional technicians accompany them and provide on-site installation and door-to-door delivery services. The Michelin official website specifically set up a Chi Jia car service center link, and the user can find the website for braking, lighting, lubricants and other full-service information. After obtaining a good experience, users will continue to use it, and then purchase in bulk from small batches. The word-of-mouth spread between user networks also attracts more potential customers for Michelin tyres and brings great benefits to the enterprise. 


\section{Interactive Marketing Model Based on User Innovation}

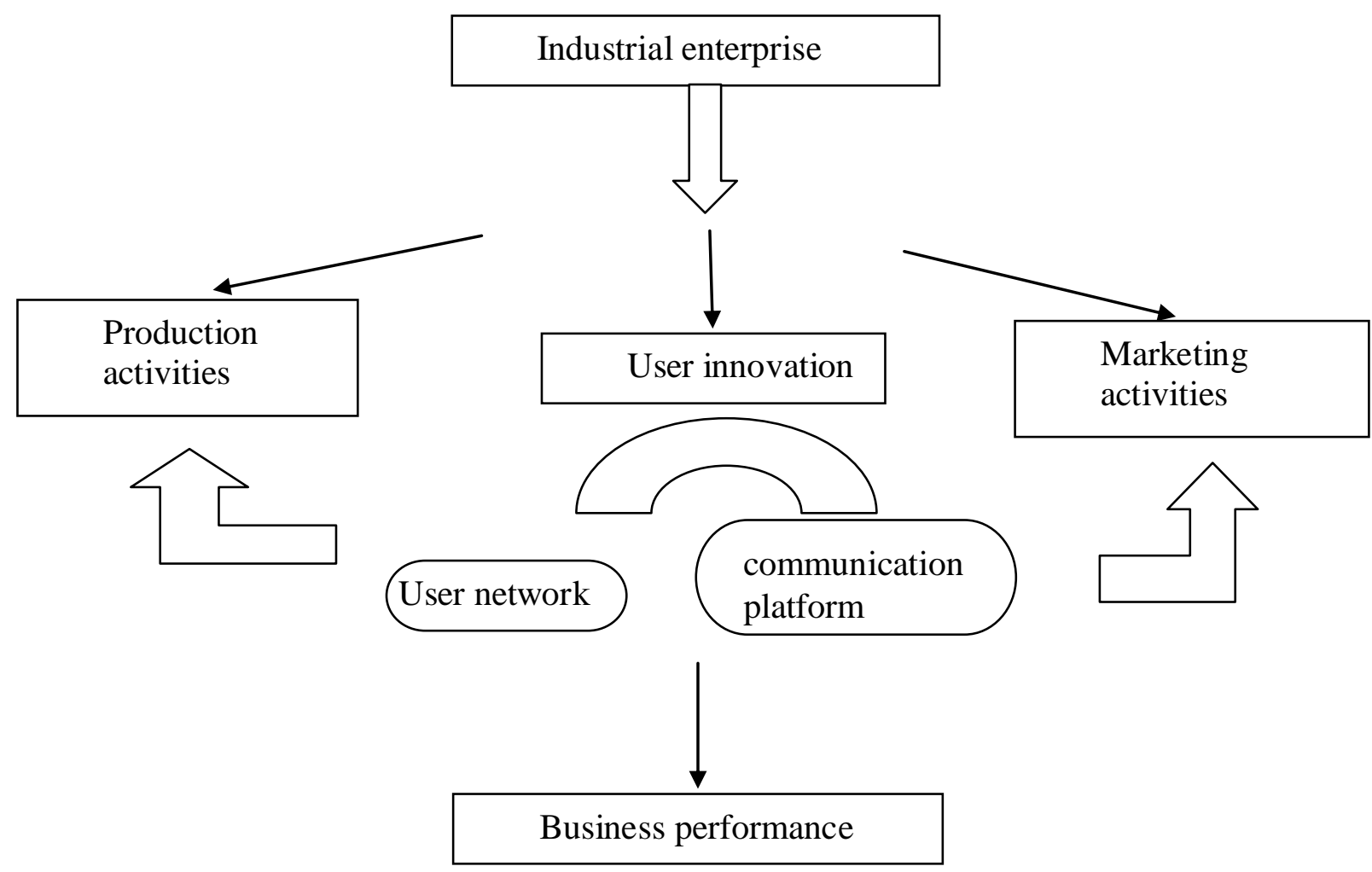

Figure 1. Interactive Marketing Mode Industrial Products Based On User Innovationl

According to the model of Michelin tyres we can summarize the mode of industrial product interactive marketing. The general idea of industrial interactive relationship marketing is: first, use consultative sales to create relationships. Enterprise product sales staff and technical experts form a team, together with users working in-depth production line, to observe common problems, then finding solutions at once.all these activities address uers, concern in the production stage ${ }^{[9]}$. In the marketing stage, enterprises should actively build and use network platform to communicate with users, when problem of products occurred, enterprises should grasp the opportunity, be responsible for the user, timely response to user requirements, to solve the problem of the user as soon as possible. Industrial enterprise use the service to provide users with a good user experience, and constantly deepen the relationship with users.Because of the characteristics of industrial products, enterprises find that users always refer to the same industry manufacturers before purchasing, so as to reduce the purchase risk.

This approach, by incorporating users into the recommended channel, makes users an voluntary propagandist.Finally, users become partners with common interests with firms and achieve win-win results.

\section{Conclusion}

In industrial marketing, users of industrial enterprises are far more innovative than those in consumer products ${ }^{[10]}$. Therefore, we should give full play to the feature of industrial users, exploring industrial interactive marketing mode based on user innovation, which combine marketing and technological innovation to solve the problem of two-way technical learning caused by user transfer knowledge which is not solved by traditional innovation theory. This paper puts forward that the interactive marketing model of industrial products can improve the innovation of the enterprise by increasing the key variable of "innovating users".what describe in this paper enriches existing literature and can effectively guide enterprises to improve performance. 


\section{References}

[1] Martin Williams, Interactive Marketing-Building loyalty one to one,Prentice Hall of Australia ,1998

[2] Eric von Hipple .The Source of Innovation [M].Oxford University,New York,1988.

[3] Meryl Davids. The Interactive of Evolution.Journal of Business Strategy.2007

[4] Liu Bing, Lu Shuang. Research on the comprehensive evaluation system of information quality based on user experience [J]. Book intelligence work, 2011,55(22):56-59. [5] Chen yu-fen, Chen jin. User participation in innovation: literature review of related theories abroad [J]. Science and technology management, 2007,(02):52-56.

[5] Liu Cuiping. Analysis on the interactive marketing method based on the Internet [J]. National business sentiment. Economic theory research, 2006,(12):35-37+29.

[6] Yongui Wang. User innovation and its management research present situation and the future [J]. Journal of foreign economics and management, 2006, (4) : 40-47.

[7] Wang Qifeng. Research on China marketing strategy of Michelin tyres [D]. Northeastern University, 2009

[8] Sreejesh,M.R. Anusree. Effects of cognition demand, mode of interactivity and brand anthropomorphism on gamers' brand attention and memory in advergames[J]. Computers in Human Behavior,2017,70:.

[9] He Yiqing, Cui Lianguang, Zhang j, Jingwei. The impact of interactive orientation on the innovation process: the mediation role of innovation ability and the regulatory role of resource patchwork [J]. Nankai management review, 2015,18(04):96-105. 